\title{
Identidade e zoomorfismo: uma análise da personagem Ananta do romance As horas nuas, de Lygia Fagundes Telles
}

\author{
Identity and animalism: an analysis of Ananta, character of the novel \\ The bare hours, of Lygia Fagundes Telles
}

\author{
FÁBIO AUGUSTO STEYER \\ JEANINE GERALDO JAVAREZ \\ Universidade Estadual de Ponta Grossa
}

Tr

\begin{abstract}
Resumo: As horas nuas, de Lygia Fagundes Telles, publicado pela primeira vez em 1989, apresenta-nos um texto fragmentado, em que a narrativa é dividida entre três personagens principais: Rosa Ambrósio, ex-atriz alcoólatra; Rahul, o gato de estimação de Rosa, alma humana reencarnada no corpo de um felino; e Ananta, terapeuta de Rosa. Neste artigo, propomos analisar de que forma o zoomorfismo relatado pela terapeuta contribui para a construção de sua identidade. A análise será feita com base nos teóricos Bauman, Hall e Woodward, e na pesquisa desenvolvida por Vera Maria Tietzmann Silva sobre a metamorfose na obra de Lygia Fagundes Telles. A discussão passará, ainda, pelo viés simbólico na investigação do significado do nome da personagem em questão, cujos resultados comprovam a ideia defendida aqui.
\end{abstract}

Palavras-chave: Identidade; Zoomorfismo; Literatura intimista; Personagem

\begin{abstract}
The bare hours of Lygia Fagundes Telles, first published in 1989, presents us with a fragmented text, in which the narrative is divided between three main characters: Rosa Ambrósio, alcoholic former actress; Rahul, Rosa's cat, a reincarnated human soul in the body of a feline; and Ananta, Rosa's therapist. In this article, we propose to examine how the animalism reported by the therapist contributes to the construction of her identity. The analysis will be based on Bauman, Hall and Woodward, and on a research developed by Vera Maria Tietzmann Silva about the metamorphosis in Lygia Fagundes Telles composition. The discussion will also be made under the symbolic bias of the meaning of the therapist's name, whose results confirm the idea defended here.
\end{abstract}

Keywords: Identity; Animalism; Intimist Literature; Character

\section{Introdução}

Último romance publicado por Lygia Fagundes Telles, "As horas nuas" (1989) traz uma narrativa fragmentada em que se entremeiam três histórias principais: Rosa Ambrósio, Rahul e Ananta. À primeira vista, tem-se como protagonista Rosa Ambrósio, uma velha atriz com problemas de alcoolismo, que não aceita o envelhecimento. Nessa linha, "As horas nuas" seriam as memórias que Rosa escreveria ${ }^{1}$ - futuro do pretérito

\footnotetext{
"Em seguida, as minhas memórias, tudo quanto é perna-de-pau já escreveu as suas, por que não eu? Hem?!... As Horas Nuas, você aprovou o título, também eu nua sem tremor e sem temor.” (TELLES, 1999, p. 43)
}

porque fica registrado que ela não chegou a fazê-lo: "Experimentei as canetas, uma de cada cor, escrever? Ainda não, escrever ainda não consigo, estou excitada, tinindo, por enquanto só posso falar, é o que estou fazendo enquanto colho o dia quente como este café" (TELLES, 1999, p. 198).

Nesse sentido, as demais narrativas serviriam como complementos dessa história principal, preenchendo as lacunas que Rosa Ambrósio deixa em aberto, ou ainda retificando determinados pontos que a ex-atriz apresentaria de forma mais generosa do que o que teria acontecido.

No entanto, se tomarmos cada narrativa, Rosa, Rahul e Ananta, separadamente, verificamos que 
elas são histórias paralelas que se justapõem no livro como narrativas fasciculadas ${ }^{2}$, contadas em capítulos intercalados, diferenciando-se em narrador ${ }^{3}$, estilo e estratégia narrativa.

Dos dezoito capítulos que compõem o romance, sete são dedicados à Rosa Ambrósio (capítulos 1, 3, 8, 12, 13, 15 e 16); seis ao gato Rahul (capítulos 2, 4, 7, 9,10 e 11); e cinco à terapeuta Ananta, dividindo-se em duas fases - antes de desaparecer e depois de desaparecer (capítulos 5 e 6 na primeira fase, e 14, 17 e 18, na segunda).

Os capítulos dedicados à ex-atriz são narrados em primeira pessoa, por ela própria. Apresentam como principal estratégia narrativa o monólogo interior direto ${ }^{4}$ e o solilóquio ${ }^{5}$. Preocupam-se em narrar principalmente o passado - lembranças da fama e da glória de Rosona; o marido morto, Gregório; seu primeiro namorado, o primo Miguel; o ex-amante, Diogo; e as peças em que atuou e cujas personagens interpretadas acabaram sendo internalizadas e compondo sua identidade, conforme defendido pela pesquisadora Luciane Beserra em sua dissertação de mestrado.

Os seis capítulos dedicados ao gato Rahul também são narrados em primeira pessoa, pelo próprio gato. Esse narrador funciona como um narrador- testemunha, na medida em que narra acontecimentos de outras personagens (Rosona, Gregório, Diogo, Dionísia, Ananta), e como narrador autodiegético, quando sua atenção se volta para lembranças de vidas anteriores. É pelos olhos do gato que vemos a decadência de Rosa Ambrósio e as misérias humanas das outras personagens.

Os capítulos dedicados à Ananta na primeira fase são narrados em terceira pessoa, por um narrador onisciente, pois temos acesso ao interior da personagem. Esses capítulos apresentam uso excessivo de parênteses - como uma intromissão explicativa na narração - e textos em itálico, que sinalizam passagens escritas pela própria Ananta em sua agenda. São nesses primeiros capítulos da personagem que entramos em contato com o Vizinho que se metamorfoseia em cavalo. Na segunda fase, o narrador também é em terceira pessoa, com acesso apenas à consciência de Renato, o primo de Ananta, que investiga seu desaparecimento. A narrativa se assemelha a histórias

\footnotetext{
Analogia com a botânica: raízes fasciculadas não possuem um eixo principal.

3 Em trabalho anterior, analisamos brevemente o narrador (ou os narradores) do romance em questão - vide referências.

4 Humphrey (1976) define monólogo interior direto como a apresentação da consciência da personagem sem interferência de um narrador. $\mathrm{O}$ texto é desordenado, aparentemente sem coesão ou coerência, pois funciona como se "um pensamento puxasse o outro".

5 Também segundo Humphrey (1976), o solilóquio - termo retirado do teatro - é semelhante ao monólogo interior na medida em que apresenta ao leitor a consciência da personagem, entretanto, o texto no solilóquio é organizado pois prevê um destinatário.
}

policiais e se mostra repetitiva, no sentido em que Renato retoma, a cada capítulo, as pistas e descobertas que fez sobre a prima.

Se as investigações de Renato Medrado não dão o resultado que se espera, ou seja, encontrar o paradeiro de Ananta, servem como complemento à construção da identidade dessa personagem, na medida em que mostram ao leitor facetas antes não comentadas, conforme veremos mais detalhadamente no terceiro tópico deste artigo.

No intuito de analisar a construção dessa personagem misteriosa, selecionamos na obra todos os trechos que continham comentários e descrições sobre a personagem Ananta. Dessa seleção, reconstituímos suas características principais vistas pelas outras personagens em contraposição ao que se apresenta nos capítulos 5 e 6, em que o narrador onisciente nos aproxima da personagem em questão. Nesse sentido, verificou-se que a personagem apresenta sete posições-de-sujeito principais e que apenas em uma delas, que chamamos "Ananta íntima", o homem que se transforma em cavalo aparece, de forma que, conforme se comprovará no decorrer da análise, constitui elemento importante na construção da identidade da pequena Ananta.

Além da análise convencional, uma pesquisa inicial a respeito da onomástica do romance demonstrou que os nomes das personagens têm relação com a identidade e com seu papel na obra. Um dos resultados dessa pesquisa sobre o nome Ananta consta neste artigo, pois corrobora nossa análise em que o Vizinho, homem-cavalo, pode ser entendido como construto da identidade da terapeuta.

$\mathrm{Na}$ mitologia hindu, Ananta é um dos nomes do deus Vishnu e significa o infinito. É simbolizada como uma serpente que engole o próprio rabo. Levando em consideração que nada numa narrativa é por acaso, ou seja, cada detalhe foi construído de forma a adquirir um sentido além do convencional, e, além disso, que o destino de Ananta é uma incógnita, não podemos deixar de ressaltar o significado de seu nome.

Apesar de parecer uma superinterpretação (cf. ECO, 2005), já que não é comum esse tipo de relação, ressaltamos que há menções aos hindus nos outros romances da autora que corroboram nossa análise. Destacamos os trechos a seguir. No romance "Verão no aquário": "Os hindus diziam que é preciso ficarmos completamente nus ao menos durante dez minutos por dia. E fechar os olhos e esperar que a alma também deixasse cair o último véu." (TELLES, 1976, p. 152). E no romance "Ciranda de pedra" temos dois trechos que remetem à Índia: "[...] discutiam sobre a procedência dos Reis Magos: - Vieram da Índia." (TELLES, 1982, p. 145) e "Ali estava o Oriente. Deslizou o indicador sobre cinco letras negras que se destacavam no colorido acinzentado: Índia. Conheceria o Ganges, sujo e misterioso como o mundo." (TELLES, 1982, p. 169). 
Portanto, há pistas que nos fazem a crer que o nome de Ananta e, consequentemente, seu significado foram levados em consideração no momento da composição da personagem.

Além disso, ressaltamos que a postura filosófica que perpassa toda a obra de Lygia Fagundes Telles, pessimista e metamórfica, também harmoniza com essa análise, já que o pessimismo schopenhaueriano bebe nas fontes da cultura oriental, principalmente o Budismo, cujas premissas compartilha com o Hinduísmo ${ }^{6}$. Voltemos.

O nome Ananta, então, aparece no Bhagavad Gita, no canto X - "Da Opulência do Absoluto". O Bhagavad Gita é um episódio do Mahabharata, um épico sânscrito que narra a história do mundo antigo. Mahabharata conta a história de um rei que teve dois filhos. Como o primogênito, Dhrtarastra, nascera cego, quem herdaria o reino seria seu irmão, Pandu. Os dois irmãos tiveram filhos, mas Pandu morreu jovem deixando sua prole aos cuidados do irmão, Dhrtarastra, que se tornou rei interinamente, até que o filho mais velho de Pandu pudesse assumir o trono.

No entanto, Dhrtarastra e seus filhos não queriam que os Pandavas (filhos de Pandu) herdassem o reino, e por isso tramaram várias vezes mata-los. Krishna, que à época havia descido à terra sob a forma humana como sobrinho da esposa de Pandu, protegia os Pandavas para que nada lhes acontecesse.

A guerra entre os primos tornou-se inevitável e Krishna, como Divindade Suprema, colocou à disposição seu exército e sua sabedoria entre os quais os filhos de Dhrtarastra e os Pandavas deviam escolher. Os primeiros optaram pelo exército, enquanto os Pandavas preferiram a sabedoria de Krishna. O episódio do Bhagavad Gita começa, portanto, no momento da batalha, em que Arjuna, um dos cinco filhos de Pandu, conversa com Krishna-mas essa parte discutiremos melhor no tópico 3.

Antes retomaremos os conceitos-chave de identidade e zoomorfismo com a finalidade de fundamentar nosso estudo. Sigamos.

\section{Identidade e zoomorfismo: conceituações}

\subsection{Identidade}

Para Bauman, a identidade é sempre uma busca pelo impossível, pelo intangível, além de só poder se manifestar a partir da diferença, da oposição: se é algo porque se não é outra coisa.

\footnotetext{
6 Fizemos uma análise comparada das obras "Ciranda de Pedra" e "As meninas" sob o viés literário-filosófico defendendo que os romances abarcam a filosofia pessimista de Arthur Schopenhauer. Este estudo foi publicado no livro "Estudos sobre Literatura, História e Cinema", organizado pelo professor Doutor Fábio Augusto Steyer (vide referências).
}

Ao comparar a identidade com as peças de um quebracabeças, Bauman explica que essa alegoria é incompleta. Ao contrário de um quebra-cabeças comprado numa loja, que contém todas as peças necessárias para se formar a imagem que conhecemos de antemão,

No caso da identidade, não funciona nem um pouco assim: o trabalho total é direcionado para os meios. Não se começa pela imagem final, mas por uma série de peças já obtidas ou que pareçam valer a pena ter, e então se tenta descobrir como é possível agrupálas e reagrupa-las para montar imagens (quantas?) agradáveis. Você está experimentando com o que tem. Seu problema não é o que você precisa para "chegar lá", ao ponto que pretende alcançar, mas quais são os pontos que podem ser alcançados com os recursos que você já possui, e quais deles merecem os esforços para serem alcançados. [...] A construção da identidade [...] é guiada pela lógica da racionalidade do objetivo (descobrir o quão atraentes são os objetivos que podem ser atingidos com os meios que se possui). A tarefa de um construtor de identidade é, como diria Lévi-Strauss, a de um bricoleur, que constrói todo tipo de coisas com o material que tem à mão... (BAUMAN, 2005, p. 55).

Nesse sentido, Bauman defende que o homem moderno ter uma identidade fixa não é algo promissor. Não se deseja mais a perfeição, pois a perfeição não é passível de mudança. Por isso, nas peças do quebracabeças que temos à mão, não se objetiva a coesão, mas a possibilidade de mudança, a incoerência, a falta de forma fixa, a desarmonia: "A identidade é uma luta simultânea contra a dissolução e a fragmentação; uma intenção de devorar e ao mesmo tempo uma recusa resoluta a ser devorado..." (BAUMAN, 2005, p. 84).

Kathryn Woodward complementa essa visão, afirmando que "essas identidades adquirem sentido por meio da linguagem e dos sistemas simbólicos pelos quais elas são representadas" (WOODWARD, 2014, p. 8), o que atribui à linguagem um papel fundamental no processo de identificação e diferenciação, tanto de forma análoga (pelos princípios da linguística saussuriana) quanto de forma constitutiva (é pela linguagem que a identidade/ diferença se manifesta).

Dessa forma, Woodward define a identidade como relacional - algo que só se pode afirmar quando há um referencial de comparação. Além disso, Woodward também introduz o conceito de posições-de-sujeito ${ }^{7}$. De forma sucinta, podemos dizer que posições-de-sujeito são as formas pelas quais nos manifestamos no espaço social, algo como as identidades que assumimos nos diferentes espaços.

\footnotetext{
Categoria foucaultiana trabalhada mais detidamente por Stuart Hall no último capítulo de "Identidade e diferença", organizado por Tomaz Tadeu da Silva (vide referências).
} 
Além de a identidade se dar pela diferença, há ainda a questão da relação desigual entre uma peça e outra do quebra-cabeças, para retomar a analogia de Bauman. Em geral, o que se assume como identidade é positivo, enquanto a diferença, o outro, é tido como negativo. De outro ponto de vista, também há a exclusão: quando se assume determinada identidade, silencia-se todas as outras, que são excluídas. Portanto, a questão da identidade não envolve aspectos passivos e equivalentes, mas relações de poder e exclusão.

No romance "As horas nuas" é possível perceber que a personagem Ananta é fragmentada. Sua identidade é formada por peças que não se encaixam perfeitamente, como o próprio fato de para os outros ela se mostrar extremamente ordeira, lógica e reservada, enquanto que na sua intimidade temos acesso a uma Ananta que tem olhares maliciosos, gosta de jogos-sem-nome em que exerce a função de predador (ou caçador), e questiona sua própria sanidade. Outra característica apontada pelo narrador onisciente do capítulo 5 confirma essa multiplicidade de posições-de-sujeito que Ananta apresenta: "Ananta sentiu a cabeça como uma lâmpada ardente que é desatarraxada do corpo e colocada (com cuidado) ao lado da lâmpada suplente e apagada" (TELLES, 1999, p. 75).

\subsection{Zoomorfismo}

Vera Maria Tietzmann Silva, em seu livro "A metamorfose nos contos de Lygia Fagundes Telles", faz uma análise detalhada sobre as diferentes metamorfoses presentes na contística de Lygia Telles, tendo como corpus um total de 55 contos. A pesquisadora defende que a metamorfose é uma questão central na obra de Lygia Fagundes Telles e, como observamos analisando os romances da autora, não se restringe apenas aos contos: "A obra ficcional de Lygia Fagundes Telles registra a todo momento a permanente mutação por que tudo passa, reprisando a cada texto, com maior ou menor destaque, o tema da metamorfose" (SILVA, 1985, p. 41).

Dentre as metamorfoses analisadas pela pesquisadora, que envolveu metamorfose física, comportamental e a morte, selecionamos o zoomorfismo, ou a metamorfose física pela transformação em animais, como objeto de estudo deste artigo.

Sobre a metamorfose física, Silva (1985, p. 53) afirma:

De um modo geral, nos contos de Lygia Fagundes Telles, a efetiva transformação física dos personagens ocorre devido a causas naturais ou a causas desconhecidas. No primeiro caso, a passagem do tempo, a instalação de uma doença ou um acidente lenta e gradativamente vão despojando o personagem de seus antigos atributos. O leitor concentra sua atenção nas reações do personagem e a metamorfose em si fica relegada ao segundo plano. No segundo caso, ao contrário, a transformação faz-se subitamente, colhendo personagem e leitor de surpresa, deixando a ambos perplexos, incapazes de se decidirem quer por uma interpretação racional quer por uma interpretação sobrenatural dos eventos. Essa vacilação compartilhada por leitor e personagem caracteriza as narrativas fantásticas.

Mais à frente a pesquisadora afirma que a ambiguidade é uma característica dos textos de Lygia Fagundes Telles, e essa indeterminação é o que faz o leitor vacilar entre uma explicação e outra, já que nada há no texto que justifique um ponto de vista em detrimento do outro. Isso também acontece no romance "As horas nuas", conforme veremos no próximo tópico.

Ao explorar a questão do zoomorfismo, Silva (1985) analisa dois contos, "Lua crescente em Amsterdã" e "A caçada". No primeiro caso, a transformação acontece por meio da evocação da palavra (ele quer ser passarinho, ela, borboleta). Os personagens dizem, para o outro e para o leitor, em que animais gostariam de se transformar ${ }^{8}$. Como num desvio de câmera num filme, a atenção do leitor e o texto focalizam a volta da menina mencionada no início do conto; quando o foco volta a ser o casal, a menina (e o leitor) encontram apenas um passarinho bicando vorazmente uma borboleta azul sob o banco9 . A dúvida permanece após o término do conto: teriam os personagens se transformado ou fora apenas coincidência?

Essa hesitação do leitor diante da ambiguidade do texto também acontece no romance em análise, quando Ananta afirma: “- Tenho um Vizinho, anunciou e enfiou a mão no bolso, como se fosse tirá-lo dali." (TELLES, 1999, p. 71) E algumas páginas adiante: "O Vizinho entrava homem e virava um cavalo" (TELLES, 1999, p. 73). Ao mesmo tempo, temos a hesitação da própria personagem diante da veracidade desses fatos: "E se tudo não passasse de um delírio? As alucinações auditivas (mais fortes que as visuais) não seriam simples consequências dessa misteriosa febre-interna que nem o termômetro (quebrado) podia medir?" (TELLES, 1999, p. 87). No entanto, após exames não detectarem nada de "anormal" na saúde de Ananta, ela volta a afirmar: "Inútil (e tola) a tentativa de transformar a realidade em fantasia, era cômodo. Mas doentio. O Vizinho existia." (TELLES,

\footnotetext{
“- Sei lá. Não quero é voltar a ser gente [...] Queria ser um passarinho [...] - Nunca me teria como companheira, nunca. Gosto de mel, acho que quero ser borboleta. É fácil a vida de borboleta? - É curta." (TELLES, 2011, p. 138).

9 "O vento soprou tão forte que a menina loura teve que parar porque o avental the tapou a cara. [...] Aproximou-se do banco vazio. Procurou os forasteiros por entre as árvores, voltou até o banco e alongou o olhar meio desapontado pela alameda deserta. [...] Guardou o bolo no bolso e agachou-se para ver melhor o passarinho de penas azuis bicando com disciplinada voracidade a borboleta que procurava se esconder debaixo do banco de pedra." (TELLES, 2011, p. 138).
} 
1999, p. 88) E a ambiguidade fica ainda maior quando Ananta resolve perguntar para sua empregada, Marlene, sobre o vizinho do sétimo andar: "Perguntou à empregada se por acaso conhecia o novo inquilino, o do sétimo andar. A moça sacudiu a cabeça, não, nem chegou a vê-lo mas parecia (informação do porteiro) um senhor muito distinto. Não se mudara ainda por causa das goteiras" (TELLES, 1999, p. 76).

O segundo conto, "A caçada", "tem sua ambientação numa loja de antiguidades, [...], tendo toda a parede do fundo tomada por uma carcomida tapeçaria. Frye esclarece que tanto as estátuas como as tapeçarias constituem variações da imagem do espelho, marcando, pois, a transição entre o real e o fantástico" (SILVA, 1985, p.58). Nesse conto, temos duas inversões de papeis: a primeira, o observador transformando-se em personagem; a segunda, de caçador transformando-se em caça. A ambiguidade fica por conta da descrição que usa palavras relacionadas a animais e a humanos, deixando o leitor em dúvida se o homem realmente se transforma em cervo ou não.

Em relação à obra que analisamos, vale ressaltar a simbologia da tapeçaria, mencionada apenas nos últimos capítulos - um detalhe no apartamento de Ananta que Renato havia deixado escapar:

- Aqui também ela não está, ele disse baixinho quando a luminosidade do sol de fim de tarde entrou brandamente pela janela que a mulher abriu. Ajustou os óculos que escorregavam do nariz para examinar de perto a tapeçaria que ocupava o centro da parede. Então era esse o terrível bosque verde-negro com a sombra de um castelo tão remoto lá no fundo que era mais para ser adivinhado do que vislumbrado. Isto estava na casa dos meus avós. Eu era menino quando vi essa tapeçaria. Não tenho ideia de como veio parar com Ananta, outro mistério (TELLES, 1999, p. 244).

Além da tapeçaria, em semelhança com o conto "A caçada", há também o gosto de Ananta pelo que ela chama de jogo-sem-nome, que, conforme a descrição abaixo, se assemelha a uma caçada:

Desde criança ela sempre gostou do jogo-sem-nome que consistia apenas em rondar o alvo desejado (e quanto!) mas sem a menor pressa em atingi-lo. Até que inesperadamente, flexionando as pernas e inclinando o corpo para trás atirava a seta certeira no centro dos círculos negros, lá onde estava desenhado o coração vermelho. Antes, o paciente ensaio da dispersão dos círculos que cercavam (e fechavam) o alvo da prancha. Deixar crescer a expectativa retardando o instante de cravar os dentes na maçã escondida no bolso da calça, a maçã ficava no fundo desse bolso. $\mathrm{O}$ encanto estava em circular com naturalidade sem levantar suspeita, o prazer (maior) estava nisso, em se expor se escondendo. $\mathrm{O}$ risco do queijo. A paciência em esperar pela hora propícia amadurecida no escuro. Ousar (com coragem) a alegria proibida. Proibida? Voltou-se bruscamente para a janela com suas cortinas caindo retas, do mesmo tom castanho-claro do tapete. Havia sol lá fora mas o tecido compacto permitia apenas a passagem de uma luz discreta (TELLES, 1999, p. 71).

Vera Maria Tietzmann Silva, no livro "A ficção intertextual de Lygia Fagundes Telles", defende, no artigo "As horas nuas, um jogo de deciframento", que o romance em questão "é um quebra-cabeças, um jogo que o leitor, à medida que avança na leitura e na medida em que conhece o conjunto da obra de Lygia, tenta montar" (SILVA, 1992, p. 30). Para a pesquisadora, "As horas nuas" foi tecido numa trama de intertextualidade com os próprios textos de Lygia Fagundes Telles, e as pistas dessa "intra-intertextualidade" seriam dadas pela própria narrativa. Nas palavras de Silva (1992, p.31):

No "puzzle" que Lygia Fagundes Telles armou faltam algumas peças, o desenho final não fica muito nítido, indagações pairam no ar quando se fecha o livro, terminada a leitura. Como todo jogo supõe parceria, alguns lances são deixados para o leitor. Veremos, neste estudo, que as peças que faltam podem ser encontradas nas intertextualizações presentes em As horas nuas. Para descobri-las, o leitor precisa ter a atenção alerta e o olhar atento para ver o que se mostra e se oculta simultaneamente [...].

Essa característica textual do romance, que seria construído como um quebra-cabeças cujas peças teriam sido retiradas de outros textos da autora, corrobora a construção fragmentada e a visão de identidade como um quebra-cabeças, de Bauman.

A pesquisadora parece tentar buscar pistas, como o fez o personagem Renato Medrado, para desvendar o enigma de Ananta nos outros textos de Lygia. Mas ressaltamos que, além de a análise não abarcar os aspectos simbólicos do texto de Lygia Telles, essa característica de intertextualidade é encontrada nos outros romances e também nos contos da autora. Talvez nosso termo "narrativas fasciculadas", utilizado de forma despretensiosa na introdução, seja pertinente para descrever uma característica da produção textual lygiana, assunto que será tratado em trabalho posterior. Por enquanto, nos contentamos em continuar nossa análise sobre a personagem sem fim.

\section{Ananta: a personagem sem fim}

No romance, Ananta é descrita fisicamente como:

[...] uma profissional sem vaidade. Disciplinada. Refletindo (como num espelho) o seu despojamento, 
já vestiu o avental. Calçou as meias brancas. Sapatos fechados, sem salto. A cabeleira crespa está rigorosamente puxada para trás e presa na nuca por uma larga fivela do mesmo tom castanho-escuro dos cabelos. (TELLES, 1999, p.69).

Em geral, os adjetivos associados a ela pelas outras personagens são: pequena e silenciosa. Quando Rosa Ambrósio conversa com a terapeuta, tenta desvendá-la um pouco mais fazendo perguntas indiscretas ${ }^{10}$. Ananta não responde.

Por fora, Ananta é um exemplo de "boa cidadã"11; por dentro ela demonstra outra personalidade - são as lâmpadas que desatarraxa e troca no momento em que precisa atender algum paciente, trecho citado ao final do tópico 2.1. Poderíamos dizer que a lâmpada que ela usa no trato social é fluorescente, pois fria, parece não deixar nada às escuras; enquanto que a lâmpada usada na sua intimidade seria incandescente, porque quente e não muito clara.

Nesse sentido, é importante atentar para o fato de que a descrição da metamorfose ocorrida no sétimo andar somente aparece quando a personagem Ananta se encontra sozinha em seu apartamento. Ou seja, quando ela usa a lâmpada incandescente (para seguir com nossa analogia). Como o texto não fecha a leitura para a existência desse Vizinho, e mesmo da metamorfose desse personagem, e já que, como dito, temos acesso a ele apenas pela consciência da terapeuta, pode-se dizer que ele faz parte da identidade da lâmpada incandescente.

No entanto, é importante observar que essa dualidade das lâmpadas, como se somente houvesse duas peças para o quebra-cabeças da identidade de Ananta, é enganosa. Retomando a narrativa do romance, podemos destacar sete posições-de-sujeito para a personagem: Ananta terapeuta; Ananta feminista; Ananta médica; Ananta prima; Ananta amiga; Ananta patroa; e, por fim, o que chamaremos de Ananta íntima, por se manifestar apenas quando a terapeuta encontra-se sozinha.

A Ananta terapeuta mostra-se centrada, organizada, silenciosa e distante:

Sei fazer a mesma cara neutra da pequena Ananta ouvindo as barbaridades que a gente vai contando naquele divã mas não aprendi o seu silêncio e perguntei uma bobagem qualquer. (TELLES, 1999, p. 158).

\footnotetext{
10 "Limpou de leve a cinza do cigarro que lhe caíra no peito. Tomou mais água. E perguntou se por acaso Ananta já tinha se masturbado. Não veio a resposta." (TELLES, 1999, p. 141).

11 "Nenhum vício. Tudo indica que era uma moça comportadíssima, daquele tipo de intelectual que tem dinheiro mas se veste com simplicidade. Bom apartamento, bom carro mas usava pouco o carro, preferia andar, gostava muito de andar. Era analista. Atendia os pacientes em casa e dormia cedo, acordava cedo. Examinei sua agenda, os pacientes não eram muitos mas ela também ajudava aí numa Delegacia de Defesa da Mulher, era feminista. Não tem inimigos aparentemente, todos falam bem dela." (TELLES, 1999, p. 183)
}

Mas essa analista já se entusiasmou com alguma coisa? O avental branco parecia ter sido passado naquele instante, nenhuma dobra. $\mathrm{O}$ discreto perfume de Lavanda. Estava de óculos. Fez um ligeiro agrado na minha cabeça e voltou-se para Rosona com uma cordialidade um tanto fria. Pela primeira vez pude ver de frente os olhos dessa pequena Ananta através das lentes de vidro branco. Tem belos olhos, descobri com certa surpresa. Destacavam-se tão luminosos na face de uma moça que a gente olha e esquece, eu disse $a$ gente. No olhar azul-cinzento, a paciência. E um certo distanciamento, que me perturbou, Gregório tinha esse jeito de olhar. (TELLES, 1999, p. 133-134).

Ananta feminista aparece principalmente relacionada ao seu trabalho voluntário na Delegacia da Mulher: "- Você parece uma pessoinha de porcelana, Ananta. Não sei como aguenta essa briga do mulherio, delegacias, jornal, creches e Deus sabe mais o quê. Sem falar nos doidos passando aqui pelo divã, eu no meio deles." (TELLES, 1999, p. 136); "[...] mas ela também ajudava aí numa Delegacia de Defesa da Mulher, era feminista." (TELLES, 1999, p. 183).

Apesar de tentar omitir esse fato, Ananta também era médica além de terapeuta, e, como tal, ela demonstra a mesma frieza profissional nas duas personas:

Ananta já entrava com seu avental e sua aparente inocência. Diogo voltou-se para ela. Tocou-lhe o braço. Falou entre os dentes: Enfarto?... Ela aproximou-se do corpo de Gregório ali exposto. Trocou com o primo algumas palavras e só então se descobriu o que inexplicavelmente ela quis sempre conservar em segredo, é médica. Médica a pequena Ananta que ninguém chamava de doutora, a mão limpa de anéis, as paredes limpas de certificados, diplomas. Compartilhou do exame com o colega quando ele recomeçou o exame. Assim que terminou, guardou os óculos no bolso. Apanhou a camisa-xadrez de Gregório e cobriu-lhe o peito. Sim, não há dúvida, ela disse. Espero que tenha sido rápido. (TELLES, 1999, p. 96-97)

Ananta prima é uma memória de Renato Medrado de quando eles eram crianças e conviviam esparsamente: “- [...] Fomos a muitas festinhas de aniversário mas exagerei quando disse que brincamos juntos, ela era de uma timidez incrível. Quando meus pais se mudaram do bairro das Perdizes para os Campos Elísios nos perdemos completamente de vista." (TELLES, 1999, p. 183).

Como amiga, Ananta era "[...] muito fechada também com as amigas, sabia ouvir as confidências. Mas pelo visto não fazia nenhuma." (TELLES, 1999, p. 240). E como patroa, demonstrava-se preocupada e humana: "E pediu à Marlene que saísse mais cedo, o céu estava se 
fechando, podia cair uma tempestade. E não precisaria se preocupar, Eu faço o meu chá.” (TELLES, 1999, p. 76).

Por fim, Ananta na sua intimidade aparece principalmente nos capítulos 5 e 6. Como já colocado, é nesse fragmento de identidade em que o Vizinho do sétimo andar nos é apresentado. Ananta íntima é caçadora à espreita (vide a citação do jogo-sem-nome no tópico 2.2), é aquela que questiona a própria sanidade (nunca colocada em questão pelos que convivem com ela). E, como demonstrado no trecho a seguir, a analista pode não ser tão paciente: "Ananta estendeu a mão para apaga-lo e tirou da gaveta a agenda maior. No retângulo branco da capa e que era reservado ao seu nome ela escreveu com letra de forma que fizera um esforço incessante para não ridicularizar, não lamentar e não desprezar as ações humanas mas compreendê-las." (TELLES, 1999, p. 70).

É na Ananta íntima que temos acesso ao Vizinho:

Ananta sentiu a cabeça como uma lâmpada ardente que é desatarraxada do corpo e colocada (com cuidado) ao lado da lâmpada suplente e apagada. Sem dor. Atarraxou a suplente e ficou esperando. Os ruídos recomeçaram, vagos no início. Espaçados. Até que foram ficando mais violentos, como se o Vizinho se atracasse com alguém numa luta feroz, intensa mas contida. Tanta vontade dos lutadores em não deixar transparecer a hostilidade dos corpos atracados e tombando borrachosos, em convulsão. E de repente ficou um só corpo a se espojar sem controle até se agarrar a alguma coisa (a porta?) antes de explodir no acesso de choro. Um choro esguichando por entre os dentes travados na obsessão do silêncio. Os soluços (silvos) diminuíram.

Ananta apertou a cabeça entre as mãos, a dor era real ou apenas memória da dor? Sentiu medo. Compaixão, agora a música era insuficiente. E se os vizinhos (quais?) descobrissem. Sabia apenas que antes da metamorfose o Vizinho se repartia em essência, exatamente como acontecia com sua cabeça na hora da dor, tinha a cabeça fixa que ela desatarraxava. E tinha a outra, mas o corpo permanecia único, aquele desesperado corpo espojante com seus acessos de choro. De tosse, lembrou e Ananta sorriu porque desconfiou que a tosse que ouviu era a própria. Quando acabou tudo, restou a música que ambos ficaram ouvindo calmos, o Cavalo e ela. Desligou o toca-discos e deitou-se febril. Mas flutuante. (TELLES, 1999, p. 75-76).

Como já colocado na introdução deste artigo, uma pesquisa inicial a respeito dos nomes das personagens demonstrou resultados interessantes e reveladores a respeito da construção do romance ${ }^{12}$. Neste artigo, nos deteremos especificamente ao nome de Ananta, que tem

\footnotetext{
${ }^{12}$ Essa pesquisa será divulgada em artigo posterior.
}

origem hindu e aparece no Bhagavad Gita, cujo enredo também consta na primeira parte deste artigo.

$\mathrm{O}$ canto $\mathrm{X}$ deste capítulo do Mahabharata, em específico, é a resposta de Krishna à pergunta de Arjuna sobre como o deus védico se manifesta no mundo. No verso 29, Krishna afirma: "Das Nagas ${ }^{13}$ de muitos capelos, sou Ananta, e entre os seres aquáticos, sou o semideus Varuna. Dos ancestrais que partiram, sou Aryana, e entre aqueles que impõem a lei, sou Yama, o senhor da morte."

Pouco antes, no verso 27, Krishna coloca que: "Dos cavalos, fique sabendo que sou Uccaihsrava, produzido durante o bater do oceano quando se queria obter néctar", o que se torna bastante relevante, uma vez que procuramos defender, neste artigo, a hipótese de que o Vizinho que se metamorfoseia em cavalo seria componente da identidade da terapeuta, Ananta, pois, na literatura védica, em especial no texto que retomamos, o Bhagavad Gita, Ananta e Uccaihsrava são manifestações de um mesmo ser, Krishna.

Ou seja, se no romance o Vizinho, homem-cavalo, aparece somente na manifestação da posição-de-sujeito Ananta íntima e, do significado hindu de seu nome, fica demonstrado que, segundo esta linha de interpretação, Ananta e uma representação equina, Uccaihsrava, fazem parte de um mesmo ser. Ou seja, o zoomorfismo do Vizinho faz parte da construção da identidade da terapeuta, na medida em que representa não só um delírio, mas toda uma posição-de-sujeito, uma peça do quebra-cabeças, que se constrói e que não se encaixa com as demais peças de Ananta.

\section{Considerações finais}

Cada vez que Ananta assume uma posição-de-sujeito, um fragmento de sua identidade ressalta e obscurece os demais, num movimento de exclusão e silenciamento, conforme retomamos no conceito colocado por Woodward no tópico 2.1. Além disso, cada peça do quebra-cabeças de Ananta não encaixa perfeitamente às outras, de forma que chegam a ser contraditórias se observarmos bem, exemplificando figurativamente o que retomamos das afirmações de Bauman nesse mesmo tópico.

No artigo "As horas nuas, um jogo de deciframento", cujos trechos retomamos no tópico 2.2, Vera Maria Tietzmann Silva defende que o romance em questão teria sido construído a partir de retalhos de outras narrativas da autora e que esses retalhos dariam pistas sobre quais caminhos seguir na leitura da obra. Apesar de ser uma análise válida, o artigo não dá conta dos detalhes simbólicos, cujos pontos de indeterminação não permitem uma leitura fechada.

\footnotetext{
${ }^{13}$ Nagas são serpentes, conforme colocado na explicação do referido verso do Bhagavad-gita (vide referências).
} 
Um desses pontos de indeterminação seria o destino da terapeuta, a cujo fim não temos acesso. Apenas podemos colher pistas, como fez seu primo, Renato Medrado, no decorrer da narrativa. Silva (1992) seleciona trechos em que ficaria clara a intertextualidade desse romance com contos da autora, como quando o primo conjectura a respeito das causas do desaparecimento de Ananta ou mesmo seu destino final.

Neste artigo, nosso objetivo não foi encontrar o destino de Ananta. Procuramos elencar características dessa personagem, vista de fora pelos outros personagens e acessando sua consciência onde era possível, de forma a defender a ideia de que a identidade é fragmentada, mutável, relacional e discursiva e que a identidade dessa personagem em específico abarca o zoomorfismo do Vizinho do sétimo andar.

Ao contrário, portanto, do que se poderia esperar, demonstramos que a ausência de fechamento da leitura da personagem Ananta corrobora com o significado simbólico de seu nome, retomado da mitologia hindu, e com a metamorfose do Vizinho, que, nessa perspectiva, faria parte, assim como Ananta, do mesmo ser.

As raízes fasciculadas das narrativas lygianas se estendem e envolvem o leitor. A leitura se torna um enveredamento pelas ramificações que podem voltar à tona na terra fértil das palavras como outras narrativas ou podem ir fundo às profundezas do desconhecido. Ananta e seu Vizinho nos puxam para baixo.

\section{Referências}

BAUMAN, Zygmunt. Identidade: entrevista a Benedetto Vecchi. Trad. Carlos Alberto Medeiros. Rio de Janeiro: Jorge Zahar Ed., 2005.

BESERRA, Luciane. Mosaico do eu: a construção da identidade em As Horas Nuas de Lygia Fagundes Telles. 2011. 95 f. Dissertação (Mestrado em Estudos de Linguagem) Universidade Federal do Mato Grosso (UFMT), Cuiabá, MT. 2011.

ECO, Umberto. Interpretação e superinterpretação. Trad. MF; revisão da tradução e texto final Monica Stahel. 2. ed. São Paulo: Martins Fontes, 2005.
HUMPHREY, Robert. O fluxo da consciência: um estudo sobre James Joyce, Virginia Woolf, Dorothy Richardson, William Faulkner e outros. Trad. Gert Meyer. São Paulo: McGraw-Hill do Brasil, 1976.

JAVAREZ, Jeanine Geraldo. O narrador em “As horas nuas", de Lygia Fagundes Telles. In: XXIII Encontro Anual de Iniciação Científica. 2014. Londrina, Paraná. Disponível em: <http:// www.uel.br/eventos/eaic/eaic2014/index.php?op=pes_anais>

JAVAREZ, Jeanine Geraldo. O mal está no gênero humano: uma análise literário-filosófica sobre o pessimismo schopenhaueriano nos romances "As meninas" e "Ciranda de pedra", de Lygia Fagundes Telles. In: STEYER, Fábio Augusto (Org.). Estudos sobre Literatura, História e Cinema. Porto Alegre: Editora Pluscom, 2016.

PRABHUPADA, Bhaktivedanta Swami. O Bhagavad-gita como ele é: edição completa como texto original em sânscrito, a transliteração latina, os equivalentes em português e significados. São Paulo: The Bhaktivedanta Book Trust, 2015.

SILVA, Vera Maria Tietzmann. A metamorfose nos contos de Lygia Fagundes Telles. Rio de Janeiro: Presença, 1985.

SILVA, Vera Maria Tieztmann. A ficção intertextual de Lygia Fagundes Telles. Goiânia: CEGRAF/UFG, 1992.

TELLES, Lygia Fagundes. As horas nuas. Rio de Janeiro: Rocco, 1999.

TELLES, Lygia Fagundes. As meninas. 6. ed. Rio de Janeiro: José Olympio, 1974.

TELLES, Lygia Fagundes. Ciranda de pedra. São Paulo: Abril Cultural, 1982.

TELLES, Lygia Fagundes. Pomba enamorada ou Uma história de amor e outros contos escolhidos. Porto Alegre: L\&PM, 2011.

TELLES, Lygia Fagundes. Verão no aquário. 4.ed. Rio de Janeiro: José Olympio, 1976.

WILKINS, W. J. Mitología hindu, vedica y puranica. Trad. Antonio Moragas. Barcelona, Espanha: Vision Libros S.A., 1980, p. 125-134.

WOODWARD, Kathryn. Identidade e diferença: uma introdução teórica e conceitual. In: SILVA, Tomaz Tadeu da (Org.). Identidade e diferença: a perspectiva dos estudos culturais. 15. ed. Petrópolis, RJ: Vozes, 2014, p. 7-72.

Recebido: 22 de agosto de 2016 Aprovado: 09 de maio de 2017 Contato: fsteyer@uol.com.br (Fábio Augusto Steyer) jgjavarez@gmail.com (Jeanine Geraldo Javarez) 